\title{
Temperament and self-based correlates of cooperative, competitive and individualistic learning preferences
}

Article

Accepted Version

Gocłowska, M. A., Aldhobaiban, N., Elliot, A., J., Murayama, K., Kobeisy, A. and Abdelaziz, A. (2017) Temperament and self-based correlates of cooperative, competitive and individualistic learning preferences. International Journal of Psychology, 52 (3). pp. 180-188. ISSN 0020-7594 doi: https://doi.org/10.1002/ijop.12206 Available at https://centaur.reading.ac.uk/43135/

It is advisable to refer to the publisher's version if you intend to cite from the work. See Guidance on citing.

To link to this article DOI: http://dx.doi.org/10.1002/ijop.12206

Publisher: Taylor and Francis

All outputs in CentAUR are protected by Intellectual Property Rights law, including copyright law. Copyright and IPR is retained by the creators or other copyright holders. Terms and conditions for use of this material are defined in the End User Agreement. 


\section{CentAUR}

Central Archive at the University of Reading

Reading's research outputs online 
Temperament and self-based correlates of cooperative, competitive and individualistic learning preferences.

Małgorzata A. Gocłowska ${ }^{1,4}$, Nawal Aldhobaiban ${ }^{2}$, Andrew J. Elliot ${ }^{1,2}$, Kou Murayama ${ }^{3}$,

\author{
Ahmed Kobeisy², Ashraf Abdelaziz ${ }^{2}$ \\ ${ }^{1}$ University of Rochester \\ ${ }^{2}$ King Abdulaziz University \\ ${ }^{3}$ University of Reading \\ ${ }^{4}$ University of Amsterdam
}

Word Count (excl. title page and abstract): 5847

Corresponding Author: Małgorzata A. Gocłowska, Department of Work and Organizational Psychology, University of Amsterdam, Weesperplein 4, 1018 XA Amsterdam, The Netherlands. E-mail: Goclowska.M@gmail.com

Acknowledgement: This project was funded by the Deanship of Scientific Research (DSR), King Abdulaziz University, Jeddah, under grant no. /1432/HiCi, and a Marie-Curie postdoctoral fellowship (FP7-PEOPLE-2013-IOF, 622331, CREA.TA). The authors, therefore, acknowledge with thanks DSR for technical and financial support, and FP7 for financial support. 


\begin{abstract}
People vary in the extent to which they prefer cooperative, competitive or individualistic achievement tasks. In the present research, we conducted two studies designed to investigate correlates and possible roots of these social interdependence orientations, namely approach and avoidance temperament, general self-efficacy, implicit theories of intelligence, and contingencies of self-worth based in others' approval, competition, and academic competence. The results indicated that approach temperament, general selfefficacy, and incremental theory were positively, and entity theory was negatively related to cooperative preferences ( $|r|$ range from .11 to .41); approach temperament, general selfefficacy, competition contingencies, and academic competence contingencies were positively related to competitive preferences ( $|r|$ range from .16 to .46); and avoidance temperament, entity theory, competitive contingencies, and academic competence contingencies were positively related, and incremental theory was negatively related to individualistic preferences $(|r|$ range from .09 to .15). The findings are discussed with regard to the meaning of each of the three social interdependence orientations, cultural differences among the observed relations, and implications for practicioners.
\end{abstract}

Keywords: social interdependence, coopertive, competitive, individualistic, achievement motivation 
Temperament and self-based correlates of cooperative, competitive and individualistic learning preferences

\section{Introduction}

How people approach achievement tasks is important to schools, teams, and organizations. In many achievement domains, complex tasks are carried out and the outcomes of one individual's actions influence those of others, leading to social interdependence. Social interdependence can be positive, leading to cooperation, or negative, leading to competition; when social interdependence is low, work occurs individually (Deutsch, 1949; Johnson \& Johnson, 2005). Most researchers agree that cooperation is beneficial and adaptive, but there is considerable debate as to the merits and demerits of competition and individualism (Johnson \& Norem-Hebeisen, 1979; Murayama \& Elliot, 2012). All would agree, however, that each is prevalent in achievement contexts, and that each is an important area of study.

Whether individuals cooperate, compete, or work independently in a group setting, depends on individual differences, as well as the structure of the situation (Deutsch, 1949; Johnson \& Johnson, 2005). To acquire a clear understanding of cooperative, competitive and individualistic preferences, it is important to consider the correlates of these orientations. The present research was designed to examine links between temperament and self-based variables (self-efficacy, implicit theories of a self-relevant attribute [intelligence], self-worth contingencies) and these social interdependence orientations. Specifically, we conducted two studies, the first in Saudi Arabia and the second in the U. S., and examined the associations among these focal variables. Linking cooperative, competitive, and individualistic preferences to personality and the self in this way promises to afford a deeper and richer understanding of these important social interdependence constructs. 


\subsection{Correlates of Cooperative, Competitive, and Individualistic Preferences}

Below we define the three focal social interdependence orientations, and note their known relevant correlates.

Cooperative preferences denote a desire for group work and a willingness to help others (Johnson \& Norem-Hebeisen, 1979). Cooperative preferences are endorsed by most students (Choi, Johnson, \& Johnson, 2011b), and for good reason: in cooperative (vs. competitive) groups individuals are more supportive of one-another and often perform better (Johnson \& Johnson, 2005). Cooperativeness correlates positively with pro-sociality (Choi, Johnson, \& Johnson, 2011a), extraversion, openness to experience, and agreeableness, (Ross, Rausch, \& Canada, 2003). Highly cooperative individuals tend to be well-adjusted: they find it easy to share their feelings and show their "true self" in social settings, their selfdescriptions are positive, and they are satisfied with themselves and their direction in life (Norem-Hebeisen \& Johnson, 1981). Negative associations have been found between cooperativeness and harm-intended aggression (Choi et al., 2011a) and the anger-hostility, depression, and vulnerability facets of neuroticism (Ross et al., 2003).

Competitive preferences characterize individuals who compare themselves with, and like to perform better than others (Johnson \& Norem-Hebeisen, 1979). Competitiveness is sometimes positively related to self-esteem and efficacy (Tjosvold, XueHuang, Johnson, \& Johnson, 2008), and sometimes unrelated (Norem-Hebeisen \& Johnson, 1981). These different associations may be a function of the link between competitiveness and conditional self-acceptance: whether competitive individuals feel good about themselves or not hinges on how well they perform in comparison to others (Norem-Hebeisen \& Johnson, 1981).

Competitiveness is positively correlated with performance-based goals (Murayama \& Elliot, 2012), deep learning strategies (King, McInerney, \& Watkins, 2012), dominance (Choi et al., 2011b), and several facets of extraversion (gregariousness, assertiveness, activity level, and 
excitement seeking; Fletcher \& Nusbaum, 2008). On the other hand, competitiveness is negatively related to several facets of agreeableness (morality, altruism, cooperation, modesty, and sympathy; Fletcher \& Nusbaum, 2008), and positively related to harm-intended aggression (Choi et al., 2011b), suggesting that benefits of competitiveness may come with costs in terms of social relations.

People with individualistic preferences like to work on their own, and claim to perform better when working alone (Johnson \& Norem-Hebeisen, 1979). Individualism can be isolating, and lead to missed opportunities for social support (Rebus et al., 2005). On the other hand, individualism can foster the ability to think independently and creatively and, in group work, promote engagement in constructive controversy (Tjosvold et al., 2008). Individualism is negatively related to self-esteem and a sense of satisfaction with one's life direction (Norem-Hebeisen \& Johnson, 1981), and is positively related to self-criticism (Choi et al., 2011b).

In the present research, we extend the existing nomological network of social interdependence orientations to include other important variables that influence individuals' self-regulation and behavior in achievement contexts: approach and avoidance temperament (Elliot \& Thrash, 2010), and self-based variables, namely, general self-efficacy (Chen, Gully, \& Eden, 2001), implicit theories of intelligence (Dweck, 1999), and self-worth contingencies (Crocker, Luhtanen, Cooper, \& Bouvrette, 2003). In focusing on this set of variables, we aim to acquire a deeper and broader understanding of cooperative, competitive, and individualistic preferences.

\section{Approach and Avoidance Temperament}

Approach and avoidance temperament are two basic personality dispositions that represent motivational sensitivities to positive (i.e., reward) or negative (i.e., punishment) stimuli, respectively. Conceptually related to other basic affective personality dimensions 
(e.g., the BIS/BAS; Amodio, Master, Yee, \& Taylor, 2008), the approach avoidance temperament is thought to represent neurobiologically-based, dispositional properties of the mind. Approach (avoidance) temperament is accompanied by a perceptual vigilance for, an affective reactivity to, and a behavioral predisposition toward positive (negative) stimuli (Elliot \& Thrash, 2010). Social connection is intrinsically valued and rewarding, therefore approach temperament is likely to be positively related to cooperative preferences. Winning competitions is societally (and perhaps even intrinsically) valued and rewarding, therefore approach temperament is likely to be positively related to competitive preferences (for related research, see Elliot \& Thrash, 2010; cf. Lochbaum, 2014; Yeatts \& Lochbaum, 2013). Norem-Hebeisen \& Johnson (1979) suggested that individualistic preferences may be linked to social anxiety and avoidance; accordingly, avoidance temperament may be positively related to individualistic preferences.

\section{Self-efficacy, Implicit Theories of Intelligence, and Self-worth Contingencies}

Self-perceptions and beliefs, as well as core dispositions, are important predictors of people's preferences and tendencies in achievement settings (Dweck, 1999). General Selfefficacy represents an individual's conviction that he or she is able to perform in a skillful and competent way across a variety of situations (Chen et al., 2001). High self-efficacy has been linked to high levels of optimism, hope, and prosocial tendencies (Caprara \& Steca, 2005), thus self-efficacy is likely to be positively related to cooperative preferences and negatively related to individualistic preferences. Self-efficacy could be positively or negatively related to competitive preferences, depending on whether the optimism and hope that it fosters, or the prosocial tendency that it engenders, prevails.

People not only vary in their perceptions of their skills and abilities, they also vary in the theories that they hold regarding the malleability of these self-relevant attributes. An incremental theory of ability represents a belief that characteristics such as intelligence can 
change over time with effort and persistence, whereas an entity theory of ability is the opposite belief - that characteristics such as intelligence are fixed by nature and immutable (Dweck, 1999). Incremental theory, like general self-efficacy, represents a resource that produces optimism and hope (Dweck, 1999), and has been linked to constructive behavior in conflict situations (Kammrath \& Dweck, 2006). Thus, much like self-efficacy, incremental theory is likely to be positively related to cooperative preferences and negatively related to individualistic preferences. Relations for competitive preferences are, again, more difficult to predict. Incremental theory may be positively related to competitive preferences if the optimism and hope that it brings generalize across all types of achievement situations, but it may be negatively related if the intrapersonal growth tendency that it engenders is a poor fit to the interpersonal, zero-sum focus of competitiveness. Entity theory is, in many respects, the antithesis of incremental theory, thus relations with entity theory may be (tentatively) expected to be the reciprocal of those for incremental theory.

In addition to self-efficacy and implicit theories of intelligence, self-worth contingencies are also important predictors of how people orient to achievement settings (Crocker et al., 2003). Self-worth contingencies are the standards that individuals must satisfy in order to have high self-esteem, and these standards may emerge from several different sources. The domains most relevant to the achievement domain are the approval of others, competition, and academic competence. Prior research has linked contingent self-worth (in general) to competitive preferences (Norem-Hebeisen \& Johnson, 1981), but the specific source(s) of this contingency is not known and will be explored herein. Prior research has also found no relation between contingent self-worth (in general) and both cooperative and individualistic preferences (Norem-Hebeisen \& Johnson, 1981); it remains possible, however, that some specific types of contingencies are related to these orientations. For example, the approval of others may be negatively related to cooperative preferences, 
because such preferences are associated with trust and open communication (Johnson \& Johnson, 1979) and likely to be unfettered by concerns about others' evaluation.

\section{The Present Research}

In the present research, we conducted two correlational studies to examine relations between the aforementioned temperament and self-based constructs and social interdependence orientations. Study 1 focused on links between approach and avoidance temperament, on one hand, and cooperative, competitive, and individualistic preferences on the other. Study 2 included the same variables used in Study 1, but also focused on links between general self-efficacy, implicit theories of intelligence, and self-worth contingencies, on one hand, and the three social interdependence orientations on the other. Together, these studies should provide clarity on the nomological nework of cooperative, competitive, and individualistic preferences.

\section{Study 1}

\subsection{Method}

\subsubsection{Participants and Procedure}

539 female undergraduates in psychology classes in Saudi Arabia participated for extra course credit. The mean age of participants was 22.5 years old (range $=18-47)$. All questionnaires were translated from English to Arabic (including back translation). Participants completed the questionnaires online during the first month of the semester.

The data for this and the following study were collected as part of larger projects on motivation and personality; portions of the data from these larger projects have been published in previous articles (for Study 1: Elliot et al., 2014, Study 2a; for Study 2: Elliot et al., 2014; Study 2b; Weideman, Tracy, \& Elliot, 2014, Study 4). In both studies, no manipulations and no data exclusions were used, and all variables that were analyzed were reported. Sample sizes represent the maximum number of participants that could be recruited 
during the predetermined period of data collection.

5.1.2 Measures (see Table 1 for descriptive statistics and reliabilities)

Approach and Avoidance Temperament. Elliot and Thrash's (2010) Approachavoidance Temperament Questionnaire (ATQ) was used to assess participants' temperament. In the measure, six items assess approach temperament (e.g., "Thinking about the things I want really energizes me") and six items assess avoidance temperament (e.g., "I react very strongly to bad experiences"). Participants responded on a 1 (not at all true of me) to 5 (extremely true of me) scale. Avoidance and approach temperament were positively correlated $(r=.35, p<.001)$.

Social Interdependence Orientations. Johnson and Norem-Hebeisen's (1979) Social Interdependence Scales (SIS) were used to assess participants' cooperative, competitive, and individualistic preferences. In the measures, seven items assess cooperative interdependence (e.g., "It is a good idea for students to help each other learn"), eight items assess competitive interdependence ("I like to be the best student in the class"), and seven items assess individualistic interdependence ("I would rather work on school work alone than with other students”). Participants responded on a 1 (not at all true of me) to 5 (extremely true of me) scale. Cooperative and competitive preferences were positively correlated $(r=.37, p<.001)$; individualistic preference was associated negatively with cooperative preference $(r=-.47, p$ $<.001)$, and was unrelated to competitive preference $(r=.03, p=.56)$.

\subsection{Results and Discussion}

Pearson Product Moment Correlations are presented in Table 1 (all $p$ values are from two-tailed tests). Approach temperament was positively related to both cooperative $(r=.36, p$ $<.001)$ and competitive $(r=.38, p<.001)$ preferences, but was unrelated to individualistic preferences $(r=.07, p<.095)$. Avoidance temperament was positively related to all three preferences: cooperative $(r=.11, p=.012)$, competitive $(r=.16, p<.001)$, and 
individualistic $(r=.09, p=.042)$.

Given that both approach and avoidance temperament positively predicted ${ }^{1}$ cooperative and competitive preferences, we conducted an additional test for differences between dependent correlations in each instance. The results revealed that the relation between approach temperament and cooperative preferences was significantly higher than that between avoidance temperament and cooperative preferences $(t=5.41, p<.001)$; likewise, the relation between approach temperament and competitive preferences was significantly higher than that between avoidance temperament and competitive preferences $(t$ $=4.80, p<.001)$. This suggests that cooperative and competitive preferences were most strongly associated with approach motivation.

In Study 2 we investigated the same relations investigated in Study 1, only with a sample from the U.S. rather than Saudi Arabia. In addition, we extended the focus to selfbased variables -- general self-efficacy, implicit theories of intelligence, and self-worth contingencies.

\section{Study 2}

\subsection{Method}

\subsubsection{Participants and Procedure}

403 undergraduates (65\% female) in a psychology class in the U.S. participated for extra course credit. The mean age of participants was 19.4 (range $=17-32$ ). Participants completed the questionnaires online: they completed the temperament questionnaire during the first week of the semester, they completed the general self-efficacy and self-worth contingency questionnaires approximately five days later, and they completed the implicit theories and social interdependence questionnaires approximately two additional days later. 6.1.2 Measures (see Table 1 for descriptive statistics and reliabilities) 
Approach and Avoidance Temperament. The ATQ (Elliot \& Thrash, 2010) used in Study 1 was used to assess participants' temperament. Participants responded on a 1 (strongly disagree) to 7 (strongly agree) scale. Avoidance and approach temperament were uncorrelated $(r=.02, p=.73)$.

Self-efficacy. Chen et al.'s (Chen et al., 2001) eight item measure was used to assess individuals' general self-efficacy (e.g., "Compared to other people, I can do most tasks very well"). Participants responded on a 1 (strongly disagree) to 7 (strongly agree) scale.

Implicit Theories of Intelligence. Dweck's (Dweck, 1999) measure was used to assess participants' incremental and entity theories of intelligence. In the measure, four items assess incremental beliefs (e.g., "No matter who you are, you can significantly change your intelligence level”) and four items assess entity beliefs (e.g., "To be honest, you can't really change how intelligent you are"). Participants responded on a 1 (strongly disagree) to 5 (strongly agree). There was a strong negative correlation of entity and incremental beliefs ( $r$ $=-.80, p<.001)$

Self-worth Contingencies. Crocker et al.'s Self-Worth Contingencies measure (Crocker et al., 2003) was used to assess participants' contingencies regarding others' approval (five items, e.g., "I can’t respect myself if others don't respect me"), competition (five items, e.g., "Doing better than others gives me a sense of self-respect"), and academic competence (five items, e.g., "I feel bad about myself whenever my academic performance is lacking”). Participants responded on a 1 (strongly disagree) to 5 (strongly agree) scale. All contingencies were positively correlated (others' and competition: $r=.35, p<.001$; others' and academic: $r=.28, p<.001$; competition and academic: $r=.51, p<.001)$.

Social Interdependence Orientations. The SIS (Johnson \& Norem-Hebeisen, 1979) used in Study 1 were used to assess participants' cooperative, competitive, and individualistic preferences. Participants responded on a 1 (strongly disagree) to 5 (strongly agree) scale. 
Cooperative and competitive preferences were uncorrelated $(r=.01, p=.841)$;

Individualistic preference associated negatively with cooperative preference $(r=-.52, p<$ $.001)$, and was unrelated to competitive preference $(r=.07, p=.19)$.

\subsection{Results and Discussion}

\subsubsection{Approach and Avoidance Temperament}

Pearson Product Moment Correlations are presented in Table 2 (all $p$ values are from two-tailed tests). As in Study 1, approach motivation was positively related to cooperative ( $r$ $=.41, p<.001)$ and competitive $(r=.25, p<.001)$ preferences. In addition, approach temperament was negatively related to individualistic preferences $(r=-.15, p<.003)$. As in Study 1 , avoidance temperament was positively related to individualism $(r=.14, p=.004)$; unlike in Study 1, avoidance temperament was not related to cooperative $(r=-.09, p=.092)$ or competitive $(r=.02, p<.70)$ preferences. Ancillary analyses testing for interactions between the temperament variables and sex revealed no significant findings.

\subsubsection{Self-relevant Variables}

Correlations for the self-relevant variables are also presented in Table 2. General selfefficacy was positively related to cooperative $(r=.30, p<.001)$ and competitive $(r=.23, p<$ $.001)$ preferences. General self-efficacy was also negatively related to individualism $(r=-.10$, $p=.053)$. Entity theory was positively related to individualistic preferences $(r=.12, p<$ $.018)$, was negatively related to cooperative preferences $(r=-.26, p<.001)$, and was unrelated to competitive preferences $(r=.04, p<.39)$. Incremental theory was positively related to cooperative preferences $(r=.25, p<.001)$, was negatively related to individualistic preferences $(r=-.12, p=.023)$, and was unrelated to competitive preferences $(r=.001, p=$ $.98)$.

With regard to self-worth contingencies, others' approval contingencies were not systematically related to any of the social interdependence orientations (all $r \mathrm{~s}<.07, p \mathrm{~s}>.22$ ). 
Competitive contingencies, on the other hand, were a positive predictor of competitive $(r=$ $.46, p<.001)$ and individualistic $(r=.13, p=.012)$ preferences, but were unrelated to cooperative preferences $(r=-.07, p<.17)$. Academic competence contingencies were a positive predictor of competitive $(r=.17, p=.001)$ and individualistic $(r=.10, p=.039)$ preferences, but were unrelated to cooperative preferences $(r=.08, p<.14)$. Ancillary analyses testing for interactions between the self-relevant variables and sex only revealed a single significant relation (indicating that the null relation between academic competence contingencies and cooperative preferences reported above masks a significant positive relation for males, $r=.31, p<.01$, but not females, $r=-.04, p<.58$.

\section{General Discussion}

The present research was designed to acquire a better understanding of the correlates of cooperative, competitive, and individualistic preferences. We sought to accomplish this aim by linking each of these social interdependence orientations to temperament and selfbased variables that have been shown to have an important influence on achievementrelevant self-regulation and behavior. Our two studies, the first in Saudi Arabia and the second in the U. S., indeed yielded several systematic relations among the focal variables. In general the findings indicated a positive pattern of relations for cooperative preferences, a negative pattern of relations for individualistic preferences, and a mixed pattern of relations for competitive preferences. These relations for each social interdependence variable are summarized in more detail in the following.

Cooperative preferences were shown to be positively related to approach temperament, positively related to general self-efficacy, positively related to incremental (and negatively related to entity) theory, and unrelated to all three achievement-related self-worth contingencies. This is a very positive network of relations, as appetitive motivation, strong 
efficacy beliefs, and a conviction that one can improve one's ability have been linked to a host of beneficial outcomes such as good performance, resilience, and strong psychological well-being (e.g., Kammrath \& Dweck, 2006). Perhaps the only way in which this pattern could be more positive would be if the relations with the self-worth contingencies were negative rather than null. In short, the present findings link cooperative preferences to a near optimal pattern of empirical relations .

Individualistic preferences, on the other hand, were shown to be positively related to avoidance temperament, negatively related to general self-efficacy, positively related to entity (and negatively related to incremental) theory of ability, and positively related to competition and academic competence self-worth contingences. This is a very negative network of relations, as aversive motivation, weak efficacy beliefs, a conviction that one's ability is immutable, and achievement-related contingencies have been linked to a host of detrimental outcomes such as poor performance, low persistence, and decrements in psychological well-being (e.g., Kammrath \& Dweck, 2006). In short, these findings portray individualistic preferences in a negative light. In fact, the pattern of findings is even more negative for these preferences than they are positive for cooperative preferences. That stated, it should be noted that the association with individualistic preferences were generally weak (all $r \mathrm{~s} \leq|.15|$ ), and weaker than those for the other preferences. As such, conclusions regarding individualistic preferences should be stated and held somewhat tentatively.

Competitive preferences were shown to be positively related to approach temperament, positively related to general self-efficacy, unrelated to incremental and entity theories, and positively related to both competition and academic competence self-worth contingencies. This is a mixed pattern, positive with regard to some variables, and negative with regard to others. Prior research has documented that competitive preferences have mixed downstream implications, sometimes leading to positive outcomes and sometimes leading to 
negative outcomes; several models of competition propose that these differential patterns emerge, in part, because of individual differences in the way that people are motivated, selfregulate, and perceive others (Murayama \& Elliot, 2012; Tjosvold, Johnson, Johnson, \& Sun, 2006). Our findings are consistent with and add concrete empirical support for such proposals.

In psychological science, research programs and entire research literatures often develop in relative isolation, and a critical task of contemporary researchers is the integration of separate lines of research. Such integration allows for a deeper, richer understanding of the constructs under consideration. We believe that the present research, as summarized in the aforementioned patterns, is a step toward this aim of integration. Specifically, the findings from our two studies highlight the fact that cooperative, competitive, and individualistic preferences do not emerge or operate in a vacuum, but instead are linked to a network of personality and self-relevant variables that give each preference its distinct conceptual flavor.

In overviewing our findings and the empirical patterns for each social interdependence orientations, we have focused only on the results that were consistent across studies. A few of the temperament results were inconsistent across studies, and this warrants consideration. In Study 1 (but not Study 2) avoidance temperament was positively related to both cooperative and competitive preferences. Several possible reasons for this inconsistency may be considered. First, Study 1 had a much larger sample size than Study 2, so perhaps the differential results were due to statistical power. However, the avoidance temperamentcooperativeness relation went in opposite directions in the two studies and the avoidance temperament-competitiveness relation was nonexistent (.02) in Study 2. Furthermore, even Study 2 has a substantial sample size, nearing 400 participants. Second, perhaps the differences between the two studies are due to sex, as the sample in Study 1 was strictly female, while the sample in Study 2 consisted of both males and females. However, this 
explanation also seems unlikely, as the pattern of correlations for the relations in question for male and female participants in Study 2 were highly similar (only one sex interaction was observed). The third, and the most likely, explanation is that the observed inconsistency is a function of cultural differences (Study 1 was conducted in Saudi Arabia and Study 2 was conducted in the U.S.). Individuals high in avoidance motivation focus on negative possibilities and seek to fit into their cultural context (Elliot, Chirkov, Kim, \& Sheldon, 2014). In cross-cultural research, Saudi Arabia has been found to be high in uncertainty avoidance (i.e., people tend to feel uncomfortable with uncertainty and ambiguity and try to minimize it; Hoftstede \& Minkov, 2014). Thus, for those high in avoidance temperament in Saudi society, both cooperative and competitive preferences may be perceived as functional, as cooperation allows one to minimize the uncertainty of social discord and competition allows one to minimize the ambiguity of one's normative standing.

One other finding was both inconsistent across studies and surprising: In Study 2 (U.S. sample), approach temperament was negatively related to individualistic preferences, whereas in Study 1 (Saudi sample) the two variables were unrelated. This suggests that individualism is more problematic motivationally (i.e., not only undergirded by the presence of avoidance temperament, but also by the absence of approach temperament) in the U.S. than in Saudi Arabia, despite the cultural emphasis being more individualistic in the U.S. than in Saudi society (Hoftstede \& Minkov, 2014). More research is needed before this puzzling pattern can be understood. More generally, more research on personality, motivation, and the self in Saudi Arabia and related countries in the region would be welcomed, as little such research has been conducted to date in this area (for an exception see Moskovsky, Alrabai, Paolini, \& Ratcheva, 2013).

Strengths of our research include the use of multiple, large samples from two different cultural contexts, and (in Study 2) the temporal separation of the measures used in the 
studies. Limitations of our research include the use of self-report measures, the correlational nature of the work, and small sizes of some of the discussed correlations. The present research may be seen as a first step in understanding the important question of the correlates of social interdependent preferences; this research lays the groundwork for more extensive empirical efforts utilizing more rigorous and diverse methodological approaches. For example, subsequent work would do well to use biological and/or behavior as well as selfreport assessments of temperament, employ within-person as well as between-person designs/analyses, and extend the focus to mediational work (e.g., examining experienced anxiety as a process accounting for the relation between avoidance temperament and individualistic preferences).

It should be noted that the approach and avoidance temperament constructs (and measures) used in the present work (Elliot \& Thrash, 2010) share conceptual (and operational) space with other broad, dispositional approach and avoidance motivation constructs (and measures) such as behavioral activation system sensitivity, incentive motivation, and extraversion for approach, and behavioral inhibition system sensitive (as originally conceptualized), harm avoidance, and neuroticism for avoidance (Carver \& White, 1994; Cloninger, Przybeck, Syrakic, \& Wetzel, 1994; Depue \& Collins, 1999; Elliot \& Thrash, 2010). Subsequent work would do well to incorporate some of these other temperament-relevant variables into this sort of research to determine the degree of similarity and difference in the links between these variables and the focal social interdependence orientations herein. Subsequent research would also do well to consider the similarities and differences between social interdependence orientations for work tasks and learning tasks per se. For example, are preferences for working in collaboration with others, in competition against others, and by oneself on a task in an office setting the same (with regard to mean level and links to other variables) as preferences for learning in collaboration with others, in 
competition against others, and by oneself in a school setting? Finally, additional research is needed to examine the psychological mechanisms responsible for the relations observed in our studies.

Before closing, we think it is important to highlight that even though a preference for individual work has been found to be linked to a problematic temperament and self-based pattern, individual work is not, in and of itself, maladaptive. Working individually has both benefits and drawbacks. On the one hand, while working on their own people miss out on opportunities for social support (Rebus et al., 2005). On the other hand, individual work can be more productive, because it is free from group processes that undermine productivity (e.g., from direct conflict, Deutsch, 1949). Brainstorming researchers, for instance, recommend that idea generation be done in different phases, both in groups and individually (Brown \& Paulus, 2002). Thus, it may be optimal for individuals not to eschew individual work, but instead to be able to flexibly switch between it and work with others, depending on the nature and demands of the work and achievement environment.

In closing, social interdependence is ubiquitous in school, sports, and work, and the way that people orient toward others in achievement contexts has important downstream implications for their affective, cognitive, and behavioral outcomes. In light of this, one important response by practicioners is to advocate for the use of cooperative group work and constructive, rather than destructive, competition in achievement settings (Johnson \& Johnson, 2005; Tjosvold et al., 2006). In addition, knowledge of the intrapersonal correlates of cooperative, competitive, and individualistic preferences not only helps explain why the observed patterns of downstream outcomes exist, but also suggests possible targets for intervention. Some of the variables that we focused on herein, such as approach and avoidance temperament, are difficult to change, and may be considered poor targets for intervention, but others such as implicit theories, are more amenable to change and seem 
optimal intervention targets (Kammrath \& Dweck, 2006). Interventions focused on helping students, athletes, and workers become more comfortable around and open to learning from their peers can also influence social interdependence orientations in a more direct fashion, and benefit downstream outcomes, accordingly. Such efforts promise to assist people to more effectively negotiate the broad swath of achievement situations that they will inevitably encounter in everyday life. 


\section{References}

Amodio, D. M., Master, S. L., Yee, C. M., \& Taylor, S. E. (2008). Neurocognitive components of the behavioral inhibition and activation systems: Implications for theories of self-regulation. Psychophysiology, 45(1), 11-19. doi:10.1111/j.14698986.2007.00609.x

Brown, V. R., \& Paulus, P. B. (2002). Making group brainstorming more effective: Recommendations from an associative memory perspective. Current Directions in Psychological Science, 11(6), 208-212. doi:10.1111/1467-8721.00202

Caprara, G. V, \& Steca, P. (2005). Self-efficacy beliefs as determinants of prosocial behavior conducive to life satisfaction across ages. Journal of Social and Clinical Psychology, 24(2), 191-217. doi:10.1521/jscp.24.2.191.62271

Carver, C.S. \& White, T.L. (1994). Behavioral Inhibition, Behavioral Activation, and Affective Responses to Impending Reward and Punishment: The BIS/BAS Scales. Journal of Personality and Social Psychology 67 (2,: 319-333. doi:10.1037/00223514.67.2.319.

Chen, G., Gully, S. M., \& Eden, D. (2001). Validation of a new general self-efficacy scale. Organizational Research Methods, 4(1), 62-83. doi:10.1177/109442810141004

Choi, J., Johnson, D. W., \& Johnson, R. (2011a). Relationships among cooperative learning experiences, social interdependence, children's aggression, victimization, and prosocial behaviors. Journal of Applied Social Psychology, 41(4), 976-1003. doi:10.1111/j.1559-1816.2011.00744.x 
Choi, J., Johnson, D. W., \& Johnson, R. (2011b). The roots of social dominance: Aggression, prosocial behavior, and social interdependence. The Journal of Educational Research, 104(6), 442-454. doi:10.1080/00220671.2010.514689

Cloninger, C., Przybeck, T., Syrakic, D., \& Wetzel, R. (1993). The Temperament and Character Inventory (TCI): A guide to its development and use. St. Louis, MO: Washingon University.

Crocker, J., Luhtanen, R. K., Cooper, M. L., \& Bouvrette, A. (2003). Contingencies of self-worth in college students: theory and measurement. Journal of Personality and Social Psychology, 85(5), 894-908. doi:10.1037/0022-3514.85.5.894

Depue, R. A. \& Collins, P. F. (1999). Neurobiology of the structure of personality: Dopamine, facilitation of incentive motivation, and extraversion. Behavioral and Brain Sciences, 22, 491-569. doi:10.1017/s0140525x99002046

Deutsch, M. (1949). An experimental study of the effects of co-operation and competition upon group process. Human Relations, 2(3), 199-231. doi:10.1177/001872674900200301

Dweck, C. S. (1999). Self-theories: their role in motivation, personality, and development (p. 178). Philadephia, PA: Psychology Press.

Elliot, A. J., Aldhobaiban, N., Murayama, K., Kobeisy, A., Gocłowska, M. A., \& Khyat, A. (2014). Impression management and achievement motivation: Investigating substantive links. Manuscript submitted for publication.

Elliot, A. J., Chirkov, V. I., Kim, Y., \& Sheldon, K. M. (2014). A cross-cultural analysis of avoidance (relative to approach) personal goals. Psychological Science, 12(6), 505510. 
Elliot, A., \& Thrash, T. M. (2010). Approach and avoidance temperament as basic dimensions of personality. Journal of Personality, 78(3).

Fletcher, T. D., \& Nusbaum, D. N. (2008). Trait competitiveness as a composite variable: Linkages with facets of the big-five. Personality and Individual Differences, 45(4), 312317. doi:10.1016/j.paid.2008.04.020

Hoftstede, G., \& Minkov, M. (2014). Culture Compass ${ }^{\mathrm{TM}}$ Database. Retrieved from http://geert-hofstede.com/countries.html

Johnson, D. W., \& Johnson, R. T. (2005). New developments in social interdependence theory. Genetic, Social, and General Psychology Monographs, 131(4), 285-358. doi:10.3200/MONO.131.4.285-358

Johnson, D. W., \& Norem-Hebeisen, A. A. (1979). A measure of cooperative, competitive, and individualistic attitudes. The Journal of Social Psychology, (109), 253261.

Kammrath, L. K., \& Dweck, C. S. (2006). Voicing conflict: preferred conflict strategies among incremental and entity theorists. Personality \& Social Psychology Bulletin, 32(11), 1497-508. doi:10.1177/0146167206291476

King, R. B., McInerney, D. M., \& Watkins, D. A. (2012). Competitiveness is not that bad....at least in the East: Testing the hierarchical model of achievement motivation in the Asian setting. International Journal of Intercultural Relations, 36(3), 446-457. doi:10.1016/j.ijintrel.2011.10.003 
Lochbaum, M. R. (2014). Approach-avoidance temperaments, goal value and efficacy, and pre-performance achievement goal contrasts: A test of mediation. Scientific Theory Journal, 117, 213-218. doi:10.5930/issn.1994-4683.2014.11.117

Moskovsky, C., Alrabai, F., Paolini, S., \& Ratcheva, S. (2013). The effects of teachers' motivational strategies on learners' motivation: A controlled investigation of second language acquisition. Language Learning, 63(1), 34-62. doi:10.1111/j.14679922.2012.00717.x

Murayama, K., \& Elliot, A. J. (2012). The competition-performance relation: a metaanalytic review and test of the opposing processes model of competition and performance. Psychological Bulletin, 138(6), 1035-70. doi:10.1037/a0028324

Norem-Hebeisen, A. A., \& Johnson, D. W. (1981). The relationship between cooperative, competitive, and individualistic attitudes and differentiated aspects of self-esteem. Journal of Personality, 49(4), 415-426. doi:10.1111/jopy.12019

Rebus, P. J., Malecki, C. K., Demaray, M. K., Elliott, S. N., Reynolds, C. R., \& Kamphaus, R. W. (2005). The relationship between social support and student adjustment: a longitudinal analysis. Psychology in the Schools, 42(7), 691-706. doi:10.1002/pits.20120

Ross, S. R., Rausch, M. K., \& Canada, K. E. (2003). Competition and cooperation in the five-factor model: individual differences in achievement orientation. The Journal of Psychology, 137(4), 323-37. doi:10.1080/00223980309600617 
Tjosvold, D., Johnson, D. W., Johnson, R. T., \& Sun, H. (2006). Competitive motives and strategies: Understanding constructive competition. Group Dynamics: Theory, Research, and Practice, 10(2), 87-99. doi:10.1037/1089-2699.10.2.87

Tjosvold, D., XueHuang, Y., Johnson, D. W., \& Johnson, R. T. (2008). Social interdependence and orientation toward life and work. Journal of Applied Social Psychology, 38(2), 409-435. doi:10.1111/j.1559-1816.2007.00311.x

Yeatts, P. E., \& Lochbaum, M. R. (2013). Coping in sport: A test of Elliot's Hierarchical Model of Approach and Avoidance Motivation. Kinesiology, 45, 186-193. 
Table 1

Study $1(\mathrm{~N}=539)$ : Pearson Product Moment Correlation coefficients between temperament variables and social interdependence orientations.

\begin{tabular}{llllll}
\hline & $\alpha$ & $M(S D)$ & \multicolumn{3}{c}{ Pearson's $r$} \\
\hline & & & COOP & COMP & IND \\
\hline Approach Temperament & .79 & $3.67(0.65)$ & $.36^{*}$ & $.38^{*}$ & .07 \\
Avoidance Temperament & .73 & $2.80(0.84)$ & $.11^{*}$ & $.16^{*}$ & $.09^{*}$ \\
\hline
\end{tabular}

Note: $* p<.05$ (two-tailed)

$\mathrm{COOP}=$ Cooperative Preferences $(M=3.50, \mathrm{SD}=0.70, \alpha=.83) ; \mathrm{COMP}=$ Competitive

Preferences $(M=3.14, S D=0.85, \alpha=.86)$. IND $=$ Individualistic Preferences $(M=2.63, S D$ $=0.87, \alpha=.86) . N$ for correlations $=536-539$. 
Table 2

Study 2 ( $\mathrm{N}=403)$ : Pearson Product Moment Correlation coefficients between temperament and self-based variables and social interdependence orientations.

\begin{tabular}{lcclll}
\hline & $\alpha$ & $M(S D)$ & \multicolumn{3}{l}{ Pearson's $r$} \\
\hline & & & COOP & COMP & IND \\
\hline Approach Temperament & .79 & $5.31(0.85)$ & $.41^{*}$ & $.25^{*}$ & $-.15^{*}$ \\
Avoidance Temperament & .79 & $4.31(1.11)$ & -.09 & .02 & $.14^{*}$ \\
General Self-efficacy & .91 & $3.93(0.63)$ & $.30^{*}$ & $.23^{*}$ & $-.10^{*}$ \\
Incremental Theory & .90 & $3.21(0.93)$ & $.25^{*}$ & .00 & $-.12^{*}$ \\
Entity Theory & .91 & $2.67(0.98)$ & $-.26^{*}$ & .04 & $.12^{*}$ \\
Others' Approval Cont. & .82 & $4.15(1.23)$ & .00 & .06 & .01 \\
Competition Cont. & .81 & $5.16(0.96)$ & -.07 & $.46^{*}$ & $.13^{*}$ \\
Acad. Competence Cont. & .79 & $5.38(0.92)$ & .08 & $.17^{*}$ & $.10^{*}$ \\
\hline
\end{tabular}

Note: $* p \leq .05$ (two-tailed)

$\mathrm{COOP}=$ Cooperative Preferences $(M=4.02, S D=0.58, \alpha=.83) ; \mathrm{COMP}=$ Competitive Preferences $(M=3.19, S D=0.76, \alpha=.86)$. IND = Individualistic Preferences $(M=2.91, S D$ $=0.78, \alpha=.89)$. Cont.$=$ Contingency; Acad. $=$ Academic.$N$ for correlations $=389-395$. 